\title{
A RESISTÊNCIA POLÍtica PRó-Egito EM CANAÃ NO PERÍODO DE AMARNA
}

\author{
The Political Resistance Pro-Egypt in Canaan in the Amarna Period
}

José Ademar Kaefer*

RESUMO: O objetivo deste artigo é apresentar a resistência política organizada pelas cidades-Estado pró-Egito frente ao avanço da revolta siquemita em Canaã durante o período das cartas de Amarna. De início, a revolta liderada por Lab'ayu, governante de Siquém, era vista apenas como um movimento isolado de mais um grupo rebelde da montanha. Mas, quando a rebelião se estendeu e teve a adesão de outras cidades-Estado e, principalmente, quando ameaçou tomar o Vale de Jezreel, celeiro de Canaã, o Egito se obrigou a entrar em ação e a organizar seus vassalos que ainda lhe eram fiéis. O estudo será feito através da análise das cartas enviadas ao Egito pelos governantes de Hazor (EA 227 e 228), de Gath-Padalla ou Rehov (EA 249 e 250) e de Jerusalém (EA 285-290) encontradas em Tell el-Amarna.

PALAVRAS-CHAVE: Cartas de Amarna. Lab'ayu. Hazor. Gath-Padalla. Jerusalém.

ABSTRACT: The aim of this article is to present the political resistance organized by the pro-Egypt city-states in face of the advance of the Shechemite rebellion in Canaan during the Amarna letters period. On the beginning the revolt led by Lab'ayu, ruler of Shechem, was seen as an isolated movement of another mountain rebel group. But when the rebellion spread out and joined others city-states, and especially when it threatened to take over the Jezreel Valley, Egypt was forced to organize its vassals who were still loyal to it. The study will be done by analyzing the letters sent to Egypt by the rulers of Hazor (EA 227 and 228), Gath-Padalla or Rehov (EA 249 and 250) and Jerusalem (EA 285-290) found in Tell el-Amarna .

KEYWORDS: Amarna letters. Lab'ayu. Hazor. Gath-Padalla. Jerusalem.

* Universidade Metodista de São Paulo (UMESP), São Paulo, Brasil. 


\section{Introdução}

A s cartas encontradas em Tell el-Amarna no final do século XIX e dos reis egípcios Amenhotep III (1390-1352) e Amenhotep IV, Akenaton (1352-1336), foi deflagrada em Canaã uma grande rebelião anti-Egito, liderada por Lab'ayu, governante de Siquém. Após a captura e morte do líder siquemita (EA 246), seus dois filhos deram sequência à luta do pai e estenderam a revolta por grande parte do território centro e sul de Canaã. No processo da insurreição, muitas cidades-Estado se posicionaram contra ou a favor da rebelião, algumas se aliaram aos rebeldes e outras se mantiveram fiéis ao Egito.

As cidades-Estado que se aliaram em contra da revolta de Lab'ayu eram lideradas por Biridiya, governante de Meguido (EA 242-246 e 365). Ou pelo menos, foi ele quem liderou a captura e morte do líder rebelde. O objetivo aqui é analisar as cartas de outras cidades-Estado que participaram da aliança anti-Lab'ayu ou que se mantiveram fiéis ao Egito resistindo ao avanço da insurreição. Além de entender o posicionamento destas cidades-Estado, estas cartas nos ajudarão a compreender melhor o desenrolar e a dimensão da revolta siquemita.

As cartas que analisaremos são as seguintes: EA 227 e 228, enviadas por 'Abdi-Shullim, governante de Hazor; EA 249 e 250, enviadas por Ba'lu-UR.SAG, governante de Gath-Padalla (?); e as EA 285-290, enviadas por 'Abdi-Heba, governante de Jerusalém.

\section{Hazor}

Hazor ou Hasôra (Tell el-Qedah) foi uma das maiores cidades, senão a maior, de Canaã no período das cartas de Amarna. Nesse tempo toda a parte baixa da cidade era habitada (KAEFER, 2012, p. 19-21). Hazor tinha ao redor de 20 mil habitantes e, durante o Bronze Médio e Tardio, matinha relações comerciais com cidades importantes da Mesopotâmia, como Mari, e provavelmente controlava toda região da alta Galileia (GOREN, FINKELESTEIN, NA'AMAN, 2004, p. 227). Apesar da sua importância, somente duas cartas enviadas de Hazor foram encontradas em Tell el-Amarna: EA 227 e EA 228. Vejamos!

\subsection{EA 227: Júbilo pela visita do faraó ${ }^{1}$}

(1-4): diga ao rei, meu senhor, a mensagem do rei da cidade de Hasuru. Aos pés do meu senhor eu tenho me prostrado.

\footnotetext{
${ }^{1}$ Seguimos as traduções ao inglês de William L. Moran. The Amarna letters. Baltimore/London: The Johns Hopkins University Press, 1992; E de Anson F. Rainey. The El-Amarna Correspondence
} 
(5-7): Eis que eu tenho guardado as cidades do rei, meu senhor, até a vinda do meu senhor a $\mathrm{mi}[\mathrm{m}]$.

(8-14): E quando eu escutei estas suas palavras então a vida do deus sol, meu deus $e$ [meu deus sol], veio diante de mim e quando ela era ouvida, eu tomei [conselho]; e meu júbilo foi completo e os deuses olharam (favoráveis) para mim. E agora estou preparando tudo até a chegada do rei, [meu] senhor.

A carta contém 28 linhas, das quais só a primeira metade é compreensível. $\mathrm{O}$ assunto todo gira em torno da visita do faraó à cidade e do júbilo do rei de Hazor em receber o visitante. O nome do rei não é citado, mas, conforme a EA 228, deve tratar-se de 'Abdi-Shullim.

Quatro aspectos chamam a atenção: o governante de Hazor se apresenta como rei (LUGAL), caso único nas cartas enviadas pelos vassalos. A carta não contém a longa fórmula de humilhação, comum às outras cartas. Hazor controla/guarda outras cidades menores (URU.DIDLI.HI.A-ni-si), pequenos centros urbanos do rei (BENS, 2016, p. 49). É a única carta de um vassalo que faz referência à visita de um faraó. Esses fatores demonstram a importância da cidade e do governante de Hazor.

Estaríamos no reinado de Amenhotep III (1390-1352)? É possível que sim, pois esse era um período politicamente mais tranquilo tanto no Egito como em Canaã. Em todo caso, não há menção de conflitos armados na carta, o que parece indicar que Hazor ou Hasuru, como aparece nas cartas (Tell el-Qedah), não está envolvida no Levante siquemita, nem contra ou a favor. Talvez, o fato de Hazor estar localizada na região norte, bastante distante da região central e sul de Canaã, onde a rebelião siquemita foi deflagrada, fosse o motivo do seu não envolvimento na grande revolta cananeia. Soma-se a isso o possível fato de Lab'ayu estar ocupado em tomar o Vale de Jezreel, não tendo o menor interesse em se meter com a poderosa Hazor, que ficava fora de sua área de ação.

\subsection{EA 228: Um servo fiel}

Todas as cartas dos vassalos contêm uma longa fórmula de apresentação, submissão e prostração, que é bastante similar em todas elas (MYNAROVÁ, 2005, p. 397-406). Por isso não convém que todas sejam transcritas, apresentaremos somente as partes de cada carta que considerarmos ter maior relevância.

(10-17): Eis que sou o servo leal do rei, meu senhor, e agora estou guardando a cidade de Hasuru, com suas aldeias [par]a o rei, meu senhor.

(18-25): Que o rei, meu senhor, dê atenção para o que está sendo feito contra a cidade de Hasuru, tua cidade, e contra o teu servo.

- A new Edition of the Cuneiform Letters from the Site of El-Amarna based on Collations of all Extant Tablets. Leiden-Boston: Brill, 2015. 
A EA 228 é bem breve e se resume basicamente a três informações: à fidelidade de 'Abdi-Shullim, ao cuidado da cidade de Hazor e suas aldeias, e às intrigas contra ele, 'Abdi-Shullim, e sua cidade. Fica novamente evidente que Hazor controla um número de outras cidades/aldeias. Na EA 364,1723, Ayyab, governante de Astarot, queixa-se ao faraó de que o governante de Hazor teria tomado três cidades dele e que teria se mantido hostil a Ayyab. Astarot fica na região leste da Transjordânia, o que quer dizer que o domínio de Hazor, além da alta Galileia, atingia também territórios do outro lado do rio Jordão (GOREN, FINKELSTEIN, NA'AMAN, 2004, p. 227). Talvez seja a esta queixa do governante de Astarot, que 'Abdi-Shullim esteja se referindo quando fala do que está sendo feito contra ele e contra sua cidade (18-25).

Em todo caso, nas duas cartas parece evidente que Hazor não está envolvida na insurreição de Lab'ayu e que ela continua fiel ao Egito (MYNAROVÁ, 2013, p. 79-88). O mesmo não se pode dizer das cartas de Gath-Padalla, que veremos a seguir.

\section{Gath-Padalla}

A localização exata de Gath-Padalla ainda é uma incógnita. Inclusive, não se sabe ao certo se ela é a capital de Ba'lu-UR.SAG, autor das cartas que iremos analisar a seguir, ou se é uma cidade secundária. Para Rainey, Gath-Padalla fica aos arredores de Jatt, localizada na margem oriental da Planície do Sharon (COCHAVI-RAINEY, 2015, p. 1565). Para Goren, Finkelstein e Na'aman (2004, p. 248-250), a capital de Ba'lu-UR.SAG seria Rehov (Tel Rehov) e que Gath-Padalla seria uma das cidades controladas pelo reino de Rehov. ${ }^{2}$ Assim, Rehov seria um dos grandes centros de Canaã norte: Rehov, com Betsã, controlavam o Vale de Jezreel Central; Siquém e Meguido o oeste; e Pella (Pihilu) o leste.

Foram encontradas duas cartas de Ba'lu-UR.SAG em Amarna, uma mais breve (EA 249) e outra mais longa (EA 250).

\subsection{EA 249: Acusação contra Ba'lu-UR.SAG}

(1-4): [dig]a [ao] rei, [meu] senho[r], a mensagem de Ba'lu-UR.SAG, seu servo. Eu caio aos pés do rei, meu senhor, seve vezes e sete vezes.

(4-17): Ao rei, meu senhor: e que ele seja informado de que meus h[omens] esteja a serviço de Milkilu. O que eu fiz a Milkilu para que ele comandasse meus homens

\footnotetext{
2 Para estes, Ba'lu-UR.SAG e Ba'lu-meher (EA 257-260 ) seriam governantes diferentes, que atuavam aproximadamente no mesmo tempo, enquanto que para Rainey seria um só e mesmo governante, $B a^{\prime} l u$-meher.
} 
como se (fossem) seus servos? Para Tagi, seu sogro, ele deu seus (próprios) homens. O que eu posso fazer, por acaso eu não sou um servo leal do rei? Meus homens [não] são capazes de me [ser]vir? Que a palavra do rei [venha] até mim para que Milkilu [escu]te e Lab'yu.

A maior parte desse tablete de 30 linhas está deteriorada e as informações na parte restante não são muito claras. Ao que parece, esta carta é resposta a uma anterior, onde o faraó acusa Ba'lu-UR.SAG de estar colocando seus homens a serviço de Milkilu, governante de Guezer, e de Tagi, sogro de Lab’ayu e governante de Ginti-Kirmil (EA 264-266). Ambos, Milkilu e Tagi, eram aliados de Lab'ayu, inimigo declarado do faraó. ${ }^{3}$

Conforme Rainey (2015, p. 1577), Ginti-Kirmil fica em algum lugar perto do Monte Carmelo e talvez nem seja a capital de Tagi, mas uma cidade que pertença a ele. Contudo, seguindo a análise petrográfica das cartas e o estudo arqueológico dos sítios, Goren (et al, 2004, p. 256-258) conclui que provavelmente o território controlado por Tagi fosse bem mais amplo e que cobrisse todo o Sharon e boa parte, senão o todo, do cume do Carmelo. Fazia fronteira com Jafa, no sul, Siquém no leste, e Meguido e Tel Yokneam no norte.

A segunda carta de Ba'lu-UR.SAG é mais longa e descreve bem a situação de desespero em que se encontram as cidades-Estado de Canaã, provavelmente durante o reinado de Amenhotep IV, Akenaton, quando a insurreição cananeia atingiu o seu auge.

\subsection{EA 250 - Um vassalo encurralado}

(4-8): Seja o rei, meu senhor informado [q] ue os dois filhos do traidor do rei, meu [s] enhor, os dois filhos de Lab'ayu, meteram suas caras para causar a perda do território do rei, meu senhor, depois do pai de[les] causar sua perda.

(9-14): E seja o rei, meu senhor, informado dos muitos dias que os dois filhos de Lab'ayu têm me atormentado: "Por que você deu a cidade de Gath-Padalla [nas] mãos do rei, teu senhor, a cidade que Lab'yu, nosso pai tomou?"

(15-22): E assim, os dois filhos de Lab'ayu dizem para mim: "Faça guerra contra os homens da terra de Gina, porque eles mataram nosso pai. Mas se Você não fizer guerra, nós seremos teus inimigos". E eu lhes respondi: "Que o Deus do rei, $[\mathrm{m}]$ eu senhor, livre-me de fazer guerra com os homens de Gina, servos do rei, meu senhor". (22-27): Eis, por favor, que o rei, meu senhor, envie um de seus altos oficiais a Biryawaza e que lhe diga: "Você irá marchar contra os dois filhos de Lab'ayu ou você será um traidor para o rei".

(28-30): Depois disso, que o rei, meu senhor, de novo escreva pa[ra m]im [a respeito] da atitude [que] seu [servo deve tom]ar contra os dois filh[os de L]ab'yu.

\footnotetext{
${ }^{3}$ Para Na'aman $(2005$, p. 153), o Egito teria dado ordens para Ba'lu-UR.SAG enviar seus homens para a corveia de Milkilu. Seria, portanto, que os reis de Canaã tinham que colocar seus trabalhadores/servos a serviço de cidades-Estado mais fortes, no caso Guezer.
} 
(31-39): A[lém dis]so, [...] Milkilu fez contato [c]om eles, um [acor]do foi celebrado entre eles [e] a[ssi]m Milikilu concordou com os dois filhos de Lab'ayu, depois de Lab'ayu causar a perda do territó[rio do] r[ei, m]eu senhor, com eles, depois que Milkilu e Lab'ayu causaram a perda.

(40-47): E assim, os dois [fi]lh[os de L]ab['a]yu ficam dizendo: "Faça guerra como fez nosso pai contra o rei, teu senhor, quando ele atacou a cidade de Shunama e contra a cidade de Burquna e contra a cidade de 'Arabu e ele as arrancou. E ele conquistou a cidade de Gath-Rimmon e ele cultivou as terras agrícolas do rei, teu senhor".

(48-52): Mas eu lhes respondi: Que o Deus do rei, meu senhor, livre-me de fazer guerra com o rei, meu senhor. O rei, meu senhor, que eu sirvo com meus irmãos que me obedecem".

(53-56): Mas o mensageiro de Milkilu não se afasta dos dois filhos de Lab'ayu nesse tempo. Milkilu continua causando a perda do território do rei, meu senhor.

(57-60): Mas eu não tenho outra intenção. Eu sirvo o rei, meu senhor, e a palavra que $o$ [re]i, meu senhor, fala, eu obedeço.

A carta traz informações importantes, entre elas, de que os filhos de Lab'ayu retomam a atividade de seu pai morto (4-8) e de que Gath-Padalla tinha sido conquistada por Lab'ayu (9-14). Ou seja, a revolta de Lab'ayu, que obrigou a intervenção do Egito, continua mesmo após a morte do grande líder rebelde. Os filhos tentam manter o controle do território conquistado pelo pai. Ba'lu-UR.SAG se encontra numa situação desesperadora. De um lado, a pressão dos rebeldes filhos de Lab'ayu, que exigem que ele tome posição e se alie a eles. Do outro, o temor de sofrer as consequências da ira do faraó. A carta, contudo, pode ter um segundo objetivo: justificar uma possível adesão de Ba'lu-UR.SAG em favor dos rebeldes, pois é comum se perceber nas entrelinhas de muitas cartas, que a confessa lealdade dos governantes nem sempre condiz com a realidade.

O faraó parece fazer pouco caso da situação em que se encontra a cidade de Gath-Padalla ou mesmo frente à rebelião generalizada em Canaã. Ba'lu-UR.SAG chega, inclusive, a recomendar, como o faraó deveria atuar: Que mande Biryawaza atacar os filhos de Lab'ayu (22-27). E depois disso, que o rei o informe como ele deve agir (28-30). Biryawaza era o governante de Damasco (EA 194-197) e, pelo que parece, é um dos poucos que ainda não estava comprometido com a revolta de Lab'ayu e seus filhos. Ba'lu-UR.SAG quer que o faraó o force a tomar partido, sob o risco de ser acusado de traidor. Ou seja, a sugestão de Ba'lu-UR.SAG faz supor que a revolta já se tinha estendido para o além Jordão, controlando a cidade de Pella (Pihilu), onde um dos filhos de Lab'ayu era governante (EA 255256), já bastante próximo da fronteira com Damasco. Esta situação de extrema instabilidade social parece indicar que estamos nos últimos anos do reinado de Amenhotep IV (Akenaton), quando a crise interna egípcia não permitia que o faraó se ocupasse com assuntos da política externa.

Nas linhas 31-39 Ba'lu-UR.SAG faz uma acusação grave contra Milkilu, governante de Guezer, de que ele esteja em conluio com os filhos de 
Lab'ayu, que os três tenham feito uma aliança e que tenham tomado terras do faraó. Sabe-se que Guezer era uma das maiores cidades-Estado de Canaã, localizada mais ao sul de Siquém, centro da insurreição. Portanto, a revolta encabeçada por Lab'ayu e seus filhos se estendeu por quase todo território centro e sul de Canaã, incluindo boa parte dos grandes centros de poder, exceto os da costa. As linhas 40-47 dão consistência a esta possibilidade ao mencionarem algumas cidades conquistadas por Lab'ayu: Shunama, Burquna, 'Arabu e Gath-Rimmon. As três primeiras situadas na encosta das montanhas em direção ao Vale de Jezreel e Gath-Rimmon em direção à costa (Js 19,45; 21,24; 1Cr 6,69). Eram terras férteis para a agricultura. Além de conquistar as cidades, que pertenciam ao Egito, Lab'ayu cultivou suas terras, o que demonstra que a revolta já se havia consumada, de posse de um extenso território, que já era administrado por ele. Gina, de cujos homens são acusados de serem os autores da morte de Lab'ayu, provavelmente ficava no Vale do mesmo nome, na região oeste do Vale de Jezreel, perto do rio Quisom (Jz 5), não longe de Meguido (NA'AMAN, 1988, p. 185). É importante lembrar que esta não é uma carta escrita por Lab'ayu ou por seus filhos, o que justificaria a possibilidade de interpretá-la como uma carta propaganda, mas por um adversário seu.

Ainda que não se saiba a localização exata de Gath-Padalla, o que parece certo é que, além de Gath-Padalla, todas as cidades conquistadas e mencionadas na carta se encontrem na região do Vale de Jezreel (BENS, 2016, p. 191), conectado com o Vale central do Jordão, um território quase todo dominado por Lab'ayu e seus filhos. É o que também coprovam as análises petrográficas das EA 249-250, que teriam sido enviadas do Vale central do Jordão, possivelmente de Betsã ou de Rehov (GOREN, FINKELSTEIN, NA'AMAN, 2004, p. 248-250). Betsã era a fortaleza base do domínio egípcio no Vale central, e Rehov, a $5 \mathrm{~km}$ ao sul de Betsã, tinha uma ocupação bem extensa no Bronze Médio e Tardio (MAZAR, 2007, p. 202-219; KAEFER, 2016, p. 39-48).

\section{Jerusalém}

Jerusalém surpreende quando vista a partir das cartas de Amarna. A cidade era provavelmente maior no período do Bronze Médio e Tardio do que na era do Ferro I e início do Ferro II (séc. X, período de Davi). ${ }^{4}$ Localizada nas montanhas de Judá, limitada ao norte pelo domínio da grande Siquém, ao oeste pela alta Sefelá, ao leste pela depressão do Jordão, e ao sul se estendendo pelo inóspito deserto de Judá, Jerusalém era apartada

4 “...no século $X$ a.C., Jerusalém não era mais do que um pequeno e pobre assentamento nas terras altas, sem construções monumentais" (FINKELSTEIN, 2015, p. 63-64). 
da região mais fértil e plana do oeste, a Sefelá. Por isso, sua economia era possivelmente mais pobre que a das cidades-Estado da Sefelá e da costa. Mesmo assim, segundo Na'aman (1996, p. 21-22), Jerusalém era semelhante a outras cidades-Estado da província egípcia de Canaã, e dominava um território amplo, que ia do sul de Betel até Hebron.

No tempo das cartas de Amarna, o governante de Jerusalém era 'Abdi-Heba, de quem foram encontradas sete cartas no Egito: EA 285-291. Segundo a análise petrográfica (GOREN, FINKELSTEIN, NA'AMAN, 2004, p. 269), cinco delas foram enviadas de Jerusalém, e as outras duas provavelmente de Betsã (EA 285) e de Guezer (EA 291). São cartas bastante longas, se comparadas a de outros vassalos. Por isso iremos transcrever somente as cartas e partes mais relevantes, no que tange ao contexto político. Das demais será feito apenas um breve comentário.

\subsection{EA 285: Guarnição em Jerusalém}

A EA 285 é uma das cartas mais breves e é bastante danificada. Nela 'Abdi-Heba pede ao faraó que envie de volta o seu mensageiro, que provavelmente foi enviado junto com alguma caravana de tributos, cereais, escravos, escravas etc., ao Egito. Isso era uma prática comum e havia sempre uma expectativa pela sua volta, pois este sempre retornava com presentes prometidos pelo faraó (EA 3,7-12). 'Abdi-Heba também reclama ao faraó de Adaya ${ }^{5}$, o comissário egípcio, que teria tomado conta da cidade de Jerusalém e construído ali uma base militar (289,30-40). Goren (et al, 2004 p. 268) acredita que por isso 'Abdi-Heba tenha ido a Betsã para enviar a carta, uma vez que a cerâmica é proveniente desta região. Ou seja, a carta não faz menção direta a uma rebelião, ainda que este possa ter sido o motivo para o estabelecimento da guarnição egípcia em Jerusalém.

\subsection{EA 286: 'Abdi-Heba difamado}

A EA 286 continua o conflito com o comissário do rei. 'Abdi-Heba se queixa de que ele está sendo difamado diante do rei pelo comissário, que se apropriou da cidade de Jerusalém. Na carta anterior era Adaya, agora o comissário é Yanhamu. 'Abdi-Heba reclama seu direito sobre a cidade e de que ele não foi posto ali nem por seu pai e nem por sua mãe, mas pelo faraó.

A tensão aumenta em relação à carta anterior. Os 'apirus, que ali estavam ausentes, agora são denunciados. 'Abdi-Heba insiste em repetir de que (47-60): "as terras do rei estão perdidas"; "os 'apirus tomaram todas elas"; "todos os governantes das cidades estão perdidos". Talvez a dramaticidade

\footnotetext{
${ }^{5}$ O nome está corrompido no tablete (RAINEY, 2015, p. 1005).
} 
de Abdi-Heba seja para que o Egito intervenha e envie as tropas regulares do seu exército.

\subsection{EA 287: Denúncia contra Milkilu}

Uma carta longa, 78 linhas. Transcrevemos as que se destacam.

(6-12): O ato que [Milkilu] tem [cometido, ele forneceu arcos e] flechas de bronze aos [homens dos filhos de La]b'ayu [...] eles estão trazendo-[os] para [a cidade de Qilt]i.

(14-17): A [cidad]e-Estado de Gezer, a cidade-Estado de Asquelon e a cidade de L[aki] sh deram a eles pão, óleo e tudo o que necessitam.

(29-31): Veja, este ato é o ato de Milkilu e o ato dos filhos de Lab'ayu, eles deram as terras do rei aos homens 'apiru.

(43-52): Que o rei investigue sobre eles (Cuchitas), tem muito pão, muito azeite, muita roupa, enquanto Pawuru, o comiss[ário] do rei, suba até a cidade-Estado de Jerusalém. Adaya se foi com a guarnição, os soldados [que] o rei tinha designado. Que o rei seja informado: Adaya [di]sse a mim: "[ve]ja, ele (o rei) me demitiu". Não a abandone! Este [ano] me envie uma guarnição [e] e envie um comissário do rei.

(60-63): O rei estabeleceu seu nome em Jerusalém para sempre, ele agora não pode abandonar a terra de Jerusalém.

Nesta carta 'Abdi-Heba faz sérias denúncias contra Milkilu, governante de Guezer, de que ele esteja fornecendo armas aos filhos de Lab'ayu. Também contra Asquelon e Lakish, de que estes forneçam azeite e pão aos rebeldes. Já na carta anterior (EA 250), Ba'lu-UR.SAG, governante de Gath-Padalla, fazia essa acusação contra Milkilu. Portanto, está evidente que Milkilu, com a capital Guezer, é um declarado aliado de Lab'ayu.

Parece haver uma disputa pela cidade de Qilti (Keila), para onde as armas são levadas. Qilti fica entre três grandes cidades-Estado: Guezer no norte, Gat no sul, e Jerusalém no leste. Qilti aparece também nas EA 279-281, onde ela é disputada por Shuwardata, governante de Gat, e 'Abdi-Heba. Ou seja, a insurreição siquemita está se estendendo cada vez mais para o sul, aonde vai conquistando cidades.

'Abdi-Heba descreve ainda a situação dramática de Jerusalém, sua cidade, que ficou abandonada à própria sorte. $\mathrm{O}$ comissário do rei, Adaya, provavelmente vendo a situação das outras cidades-Estado, retirou-se com sua tropa de Jerusalém por temor aos rebeldes e voltou para Gaza. Se antes 'Abdi-Heba se queixava porque o comissário havia tomado o governo da cidade (EA 285 e 286), agora ele reclama porque o comissário foi embora e a cidade ficou desguarnecida. Para salvar sua cidade, o governante apela agilmente para a autoestima do faraó: "O rei estabeleceu seu nome em Jerusalém para sempre, ele agora não pode abandonar a terra de Jerusalém" (60-63).

A carta faz menção ainda, linhas 53-59, a um envio de oito caravanas ao Egito, contendo grande quantia de prata e prisioneiros. Todo o contingente 
teria sido saqueado na planície de Ayalon e de que 'Abdi-Heba não teria como enviar outra caravana. Uma caravana com dinheiro, prisioneiros de guerra e alimentos tem poucas chances de chegar ao Egito tendo que passar por um território em total convulsão.

Portanto, estamos no ápice da revolta siquemita: a grande Guezer, com Milkilu, aliou-se a Lab'ayu e seus filhos, Qilti está sendo conquistada, Lakish e Asquelon, na costa mediterrânea, são solidárias e fornecem pão e azeite de suas férteis terras aos rebeldes. Os 'apirus tomam territórios e Jerusalém está isolada e abandonada à própria sorte. ${ }^{6}$

\subsection{EA 288: Jerusalém isolada}

(23-33): Que o rei se aconselhe referente à sua terra. Perdida está a terra do rei, toda ela. Eu estou isolado. Há uma guerra aberta contra mim, desde as montanhas de Seir até a cidade de Gath-Carmel. Todos os governantes estão em paz, mas eu estou em guerra. Tornei-me como um 'apiru e não posso contemplar os dois olhos do rei, meu senhor, por causa da guerra contra mim. Sou como um navio no meio do oceano.

(34-40): A mão forte do rei tomou a terra de Nahrima e a terra de Cush, mas agora os 'apirus tomaram muitas cidades do rei. Não sobrou nenhum governante do rei, meu senhor, todos estão perdidos. Veja, Turbazu foi morto no portão da cidade de Silo. E o rei não fez nada. Veja, os servos que se uniram aos 'api[r]u mataram Zimreda de Lakish e Yaptih-Hadda foi morto no portão da cidade de Silo. O rei não fez nada. [Por] que não os chamou para prestar contas?

A carta segue, com 'Abdi-Heba pedindo o envio de tropas regulares (48-61).

Temos outra carta longa, 66 linhas, e 'Abdi-Heba segue com seu estilo dramático pintando um quadro bastante pessimista da situação: a guerra contra ele vai "desde as montanhas de Seir até a cidade de Gath-Carmel". Ou seja, de leste a oeste do Levante. E ele se encontra sozinho "como um barco no meio do oceano".

Parece que Abdi-Heba foi chamado a se apresentar diante do rei, provavelmente por causa das denúncias feitas por seus colegas, como Shuwardata (EA 280). Por isso é que no início da carta (7-22), 'Abdi-Heba se queixa de que está sendo difamado e até chamado de 'apiru. Ele busca se justificar dizendo que não pode contemplar os dois olhos do rei, por causa da guerra contra ele. E endossa de que ele é muito mais que um governante, é um soldado fiel do rei, um entregador de tributos. ${ }^{7}$ Como suporte lista um alto número de escravos e mulheres que ele teria enviado ao rei (EA 287,53-59), mesmo assim teria sido abandonado.

\footnotetext{
${ }^{6}$ No final da carta (64-70) tem ainda uma nota curiosa, 'Abdi-Heba faz um apelo ao escriba do rei, aquele que traduz e lê a carta para o faraó, para que ele apresente palavras eloquentes ao rei. Ou seja, 'Abdi-Heba sabe muito bem que o efeito da carta depende muito do tom e do espírito de como ela é lida ao faraó.

${ }^{7}$ Esta é a melhor definição da função dos governantes das cidades-Estado de Canaã.
} 
'Abdi-Heba ainda chama a atenção do rei, de este ter conquistado Nahrima e Cush, no alto Egito, mas que não tem se preocupado com a situação de Canaã. Menciona, inclusive, colegas governantes que foram mortos em suas cidades: Turbazu e Yaptih-Hadda, mortos no portão da cidade de Silo, e Zimreda em Lakish. Contudo, o rei nada faz.

Uma expressão no início da carta pode ajudar a identificar a época aproximada em que a carta foi escrita. Além da fórmula clássica de apresentação e submissão, a EA 288 tem um complemento, que é: "O rei, meu senhor, assentou seu nome no nascente do sol e no poente do sol" (4-7). É possível que esta "oração" seja uma referência ao culto ao Deus Aton, o disco solar, introduzido por Akenaton. Estaríamos, portanto, entre os anos 352-336, provavelmente após a prisão de Lab'ayu, quando os filhos retomam o projeto de libertação do pai.

\subsection{EA 289: Mais denúncias de 'Abdi-Heba}

(5-10): Veja, Milkilu não se apar[tou] dos filhos de Lab'ayu e dos filhos de Arsawa para conquistar as terras do rei para si mesmos. Como governante de cidade que fez tal coisa, por que o rei não o chamou a prestar contas?

(11-17): Este foi o ato que Milkilu e Tagi realizaram: eles tomaram Rubutu. E agora sobre Jerusalém: se esta terra pertence ao rei, por que ela não diz respeito ao rei como Gaza, e simplesmente é isolada?

(18-24): Veja, o território da cidade de Gath-Carmel pertence a Tagi e os homens de Gath estão guardando Bet-Shean, "façamos como Lab'ayu!" E eles deram a terra de Siquém aos 'apiru.

(25-29): Milkilu escreveu para Tagi e para os filhos de (Lab'ayu): "Sejam homens! Concedam todas as demandas aos homens de Qilti e vamos isolar Jerusalém".

(30-40): A guarnição que você enviou sob a responsabilidade de Haya, filho de Miyare, Addaya a tomou e estabeleceu na sua casa na cidade de Gaza e vinte homens ele enviou para o Egito. Que o rei seja informado: Não há guarnição da realeza comigo. Como o rei vive, assim é verdade que o seu oficial, Pawuru, me deixou. Ele está na cidade de Gaza.

(41-46): Que o rei pense e que o rei envie uma guarnição de cinquenta homens para proteger [sua] terra. Toda a terra do rei foi abandonada. Envie Yinhamu, que ele seja informado sobre a terra do rei.

'Abdi-Heba continua suas acusações contra Milkilu, seu vizinho e inimigo confesso, incluindo agora também Tagi e a cidade de Gat. A acusação é mesma, após a morte de Lab'ayu de Siquém (EA 246), a revolta continua com os filhos, assim como a coalizão anti-Egito, da qual fazem parte Milkilu, governante de Guezer, Tagi, governante de Ginti-Kirmil (EA 264-266) e Shuwardata, governante de Gat (EA 278-284, 366). É possível também que por trás das acusações esteja um antigo conflito entre cidades-Estado vizinhas, como no caso aqui, entre Jerusalém e Guezer, que ficam bem próximas uma da outra.. 
O centro da rebelião é Siquém, que parece continuar sendo governada por um dos filhos de Lab'ayu, após a morte do pai. Conforme Raynei (2015, p. 1595), as linhas 18-24 são uma comprovação de que Siquém era o centro das ações de Lab'ayu e seus filhos, e não Pella, como defendem alguns. O interessante é que, pela carta, os rebeldes estão cercando também Betsã, que era o centro administrativo e militar do Egito no centro-leste do Vale de Jezreel. Ou seja, se os filhos de Lab'ayu conquistassem Betsã controlariam boa parte do celeiro egípcio.

'Abdi-Heba afirma que um dos objetivos dos rebeldes é isolar Jerusalém, que por sua posição geográfica, nas montanhas de Judá, tinha já essa característica. Por isso, ele mais uma vez pede que o rei envie uma guarnição para proteger Jerusalém, pois, Pawuru, o comissário, a abandonou e voltou para Gaza, que era a base militar e administrativa do Egito na Costa. Aliás, 'Abdi-Heba reclama do porque o rei não dá a mesma atenção à Jerusalém como dá à Gaza (30-40).

Estamos, portanto, no período pós-morte de Lab'ayu, quando os filhos continuam a guerra do pai. A denúncia de 'Abdi-Heba deixa evidente os inimigos do Egito e as cidades em rebelião: os filhos de Lab'ayu, que continuam a guerra do pai; Milkilu, governante de Guezer; Tagi, sogro de Lab'ayu e governante de Ginti-Kirmil; os 'apirus e os filhos de Arsawa, grandes inimigos do rei (MORAN, 1992, p. 380). Jerusalém continua fiel, assim como Gaza e as cidades costeiras (?), Betsã, Meguido, Hazor e Gath-Padalla.

\subsection{EA 290: Disputas com Guezer e Gat}

(5-13): [Ve]ja, quanto ao ato que Milkilu e Shuwardata cometeram contra a terra do rei, meu senhor. Eles reuniram as tropas da cidade de Gezer, as tropas da cidade de Gath e as tropas da cidade de Qilti (Keila) (e) conquistaram a cidade de Rubutu. A terra do rei passou para os 'apirus.

(14-18): e agora, além disso, uma cidade pertencente a Jerusalém, cujo nome é Bit-NIN.IB, uma cidade do rei, passou para o lado dos homens da cidade de Qilti (Keila).

(19-21): Que o rei escute a 'Abdi-Heba, seu servo, e que ele envie tropas regulares e que a terra do rei retorne para o rei.

Uma carta de 30 linhas, mais breve que as anteriores. 'Abdi-Heba continua suas acusações contra a aliança anti-Egito, da qual fazem parte Milkilu, governante de Guezer, e Shuwardata, governante de Gat, que teriam reunido os homens de Guezer, Gat e Qilti (Keila) e conquistado a cidade de Rubutu, que fica entre Guezer e Jerusalém. É, portanto, uma carta muito similar às duas anteriores. Com a diferença de que aqui a briga é mais diretamente com Milkilu, de Guezer, e Shuwardata, de Gat, inimigos mais 
próximos de 'Abdi-Heba. Gat, Guezer e Jerusalém formam um triângulo geográfico. Os territórios dos três fazem divisa entre si, um dos motivos pelo qual haver constantes disputas entre eles.

Também a conquista de Rubutu já foi mencionada na EA 289. Assim também a ameaça de atacar Jerusalém, que aqui já perdeu para os rebeldes uma de suas cidades, Bit-NIN.IB, de localização incerta (MORAN, 1987, p. 389). O curioso é que não há menção a Lab'ayu e a seus filhos. O que parece confirmar que as cidades-Estado aproveitavam o momento da convulsão social também para se apoderar das cidades/aldeias vizinhas.

Há ainda mais uma carta enviada por 'Abdi-Heba, a EA 291. É uma carta bastante danificada e por isso não é possível traduzi-la. Ela é normalmente atribuída à Jerusalém, (LIVERANI, 1998, p. 88), mas o estilo de sua escrita aponta para Guezer como local de sua origem (GOREN, FINKELSTEIN, NA'AMAN, 2004, p. 269).

Em síntese, pelo que apresentam as cartas de 'Abdi-Heba, Jerusalém não foi conquistada por Lab'ayu e seus filhos, talvez porque não tivesse importância geográfica e nem econômica para a insurreição siquemita. Também não há menção direta de que ela tenha participado da aliança anti-Lab'ayu e da captura do líder rebelde. O que se vê é uma Jerusalém isolada e envolvida em constantes conflitos por território com as cidades-Estado vizinhas, comprometidas com a revolta, como Guezer e Gat. "Solitária" na região montanhosa do sudeste, Jerusalém se manteve fiel ao Egito todo o tempo.

\section{A coalizão pró-Egito}

Assim como a rebelião siquemita construiu uma coalizão de cidades-Estado anti-Egito, constituída basicamente por Siquém, Guezer, Gat, Ginti-Kirmil e Pella, a resistência organizou uma coalizão de cidades-Estado pró-Egito. Esta era formada basicamente por Biridiya, governante de Meguido; Yashdata, cuja cidade-capital é desconhecida (EA 248); 'Abdi-Shulim, governante de Hazor, em cujas cartas há evidência de confessa lealdade ao Egito; Ba'lu-UR.SAG, de cuja cidade-capital não há claras evidências, mas que provavelmente fosse Gath-Padalla ou Rehov; 'Abdi-Heba, governante de Jerusalém, que pelas suas cartas não participou diretamente da captura de Lab'ayu, mas que manteve constantes conflitos com as cidades-Estado pró-Lab'ayu, como Guezer e Gat.

Nas entrelinhas das cartas analisadas ainda é possível identificar outras cidades-Estados que participaram da coalizão pró-Egito. Entre elas estão particularmente as cidades costeiras, como Gaza, Asquelón e Asdod. Ou ainda, conforme a EA 366,17-28, Aco e Achshaph (GOREN, FINKELSTEIN, 
NA'AMAN, 2004, p.). Na EA 245,24-40, Biridiya, governante de Meguido, relata que Surata, governante de Aco, teria se comprometido a levar Lab'ayu vivo ao Egito, o que leva a entender de que ele teria participado de sua captura.

\section{Teologia}

Em geral, as cartas analisadas, assim como as demais cartas dos vassalos cananeus, não tratam dos interesses do povo, da sua cultura, religiosidade, cotidiano etc. O que temos em abundância são confissões de culto ao faraó, especialmente nas introduções, que, provavelmente, tinham também a função de expressar a fidelidade e submissão dos governantes. Imagina-se que os escribas já soubessem estas fórmulas introdutórias de adoração ao faraó de memória. Imagina-se também, que o culto ao faraó não se reduzia ao governante, mas era uma prática exigida de toda a corte, com seus altos oficiais etc. Um exemplo ilustrativo pode ser a carta que Tagi, governante de Ginti-Kirmil, enviou ao faraó, com o seguinte dizer:

\section{EA 266,8-25:}

Eu olhei nesta direção e eu o[lhei na]quela direção, mas não tinha [lu]z. Então eu [o] lhei [na] direção do rei, [meu senhor, e l]á tinha luz. Assim, [eu tenho] posto minha [fac]e para se[rv]ir [o re]i, meu senhor. Um tijolo pode se mover [de]baixo de outro [tijolo], mas eu não vou me mover de[bai]xo dos pés do [re]i, meu senhor.

Como se vê, para o governante e os seus, o faraó é o único ponto de onde emana luz. É possível que a intensificação desta ideologia seja oriunda de Amenhotep IV (Akenaton), que introduziu uma nova teologia no Egito: o monoteísmo. Em seu reinado ocorre uma grande mudança na religião egípcia, a substituição do deus Amon pelo deus Aton, o disco solar, como deus supremo. De aí o nome da cidade de Amarna, que então era chamada de Aketaton: horizonte de Aton.

A nova teologia centra a atenção na família real, que aparece em várias pinturas adorando o disco solar. Também ocorre uma mudança na arte. Se os reis anteriores eram sempre pintados de pé e em movimento, com ombros largos, rosto quadrado, musculosos e semblante guerreiro, Akenaton aparece sentado, com a esposa Nefertiti e os filhos, carinhoso, braços longos, mãos compridas e dedos finos, sem musculatura, estatura delgada e alta, cabeça, pescoço e rosto alongados, com expressão suave, coxas e quadris avantajados (KEMP, 2012, 31).

Com Amenhotep IV (Akenaton), a ideologia do rei-deus vai dar lugar à ideologia do deus-rei. Ou seja, Akenaton está no mundo, na figura do rei e sua família. Isso muda a própria visão de mundo, não para fora, mas 
para dentro, para a história. Por isso, toda a atenção deve estar voltada ao rei e sua família. O resto não importa. Provavelmente foi essa teologia que fez Akenaton perder o interesse pela política, pela guerra e pelo que acontecia nos longínquos territórios conquistados pelos seus antecessores. Foi ela que permitiu para que Lab'ayu e seus aliados começassem a sonhar com uma terra livre.

\subsection{A revolta de Lab'ayu e Israel}

A revolta de Lab'ayu, sua expansão e domínio a partir de Siquém em direção ao Vale de Jezreel e em direção à Transjordânia, é bastante similar ao sucedido com o movimento de libertação liderado por Saul (1Sm 8-31). O reino saulida também começou nas montanhas centrais de Canaã, só um pouco mais ao sul, na região que mais tarde viria a ser chamada de território de Benjamin. Seu entorno eram as aldeias morfologicamente aparentadas: Gibeá de Saul, Gibeá de Benjamin, Gibeá de Elohim, Gebá e Gibeon (1Sm 9-(12)14). Todas estas aldeias têm em comum a raiz $g b^{\prime}$ (montanha), o que caracteriza sua identidade de "reino da montanha" (KAEFER, 2016, p. 402-426). Dali o reino saulida se estendeu para o norte, em direção à montanha de Efraim, beirando o Vale de Jezreel e para o leste, na direção de Jabes de Gilead, na Transjordânia. Quando Saul e os seus ameaçaram conquistar o Vale de Jezreel, as cidades-Estado da planície começaram a organizar a resistência. $\mathrm{O}$ temor de perder o controle sobre o Vale de Jezreel obrigou o Egito a entrar em ação. O rei Sheshong I (séc. X) iniciou uma grande campanha de repressão com seu poderoso exército e aniquilou o reino rebelde (FINKELSTEIN, 2006, p. 171-193). Somente vários anos depois, com os omridas, início do século IX a.C., é que surgiria na mesma região montanhosa o primeiro reino/Estado independente, chamado Israel.

Não se sabe como foi o fim da revolta de Lab'ayu e seus filhos, mas a semente de libertação foi plantada. E ela foi germinando lentamente até eclodir.

\section{Conclusão}

A análise das cartas enviadas ao Egito por 'Abdi-Shullim, governante de Hazor, por Ba'lu-UR.SAG, governante de Gath-Padalla ou Rehov, e por 'Abdi-Heba, governante de Jerusalém, mostra que a revolta iniciada por Lab'ayu, governante de Siquém, contra o domínio egípcio, foi continua-

\footnotetext{
${ }^{8}$ Veja o amplo debate sobre a realocação da data da campanha de Sheshong I, normalmente aceita como tendo sido no ano 926 a.C. (1Rs 14,25-28). In: FINKELSTEIN, 2015, p. 61.
} 
da pelos filhos após a morte do pai. O levante começou em Siquém, se estendeu para o sul, onde conquistou importantes aliados, como Milkilu, governante de Guezer, e Shuwardata, governante de Gat. Estendeu-se também para o oeste, sobre a cidade-Estado de Ginti-Kirmil, onde reinava o sogro de Lab'ayu, e para o leste, sobre a cidade-Estado de Pella, onde governava um dos filhos de Lab'ayu.

Contudo, a revolta não teve vida fácil, pois as cidades-Estado que controlavam a planície, como Meguido, Gath-Padalla (Rehov?), Betsã e as cidades costeiras, como Gaza, Asdod, Asquelón, Aco etc., organizaram uma coalizão anti-Lab'ayu. E, com o auxílio do exército egípcio, capturaram e mataram Lab'ayu e, depois, mantiveram sua luta contra a insurreição combatendo os filhos de Lab'ayu. Houveram ainda outras cidades-Estado, que se não participaram diretamente da captura de Lab'ayu e talvez nem integrassem a coalizão pró-Egito, mantiveram-se fiéis ao Egito todo o tempo. Entre estas se encontravam Hazor e Jerusalém. Esta última mantinha uma constante luta com as cidades-Estado vizinhas, especialmente com Guezer, pelo controle do seu território.

\section{Referências}

BENS, C. B. The Land before the Kingdom of Israel: a History of the Southern Levant and the People who populated It. Winona Lake: Eisenbrauns, 2016.

COCHAV-RAINEY, Zipora (ed.). The El-Amarna Correspondence - A new Edition of the Cuneiform Letters from de Site of El-Amarna based on Collations of all Extant Tablets. Leiden-Boston: Brill, 2015. v. II.

FINKELSTEIN, I. O Reino esquecido: arqueologia e história de Israel Norte. São Paulo: Paulus, 2015.

FINKELSTEIN, I. The Last Labayu: King Saul and the Expansion of the First North Israelite Territorial Entity. In: AMIT, Y.; BEN ZVI, E.; FINKELSTEIN, I; LIPSCHITS, O. (Orgs.). Essays of Ancient Israel in its Near Eastern Context: a Tribute to Nadav Na'aman. Wininona Lake: Eisenbraus, 2006. p. 171-193.

FINKELSTEIN, I.; NA'AMAN, N. Shechem of the Amarna Period and the Rise of the Northern Kingdom of Israel. Israel Exploration Journal, Tel Aviv, v. 55, n. 2, p. 172-193, Jan. 2005.

GOREN, Y.; FINKELSTEIN, I.; NA'AMAN, N. Inscribed in Clay: Provenance Study of the Amarna Letters and other Ancient Near Eastern Texts. Tel Aviv: Tel Aviv University, 2004.

KAEFER, J. A. Arqueologia das terras da Bíblia. São Paulo: Paulus, 2012.

. À procura de Saul! Uma análise de Primeiro Samuel 9-(12)14. Horizonte, Belo Horizonte, n. 42, p. 402-426, 2016. . Arqueologia das terras da Bíblia II. São Paulo: Paulus, 2016. 
KEMP, B. The City of Akhenaten and Nefertiti: Amarna and its people. London: Thames\&Hudson Ltd, 2012.

LIVERANI, M. Le lettere di el-Amarna: Le lettere dei "Piccoli Re". Brescia: Paideia, 1998. v. 1.

MAZAR, A.; PANITZ-COHEN, N. It is the Land of Honey: Beekeeping at Tel Rehov. Near Eastern Archaeology, Jerusalém, v. 70, n. 4, p. 202-219, 2007.

MORAN, W. L. The Amarna letters. Baltimore/London: The Johns Hopkins University Press, 1992.

MYNAROVÁ, J. A Comment on the Opening Passages of the Amarna Letters: Its Structure and Its Addres. Archiv orientální - Quaterly Journal of African and Asian Studies, v. 73, p. 397-406, 2005.

MYNAROVÁ, J. Being a Loyal Servant. Egypt and the Levant from the Perspective of Juridical Terminology of the 18th Dynasty. Journal for Ancient Near Eastern and Biblical Law, n. 19, p. 79-88, 2013.

NA'AMAN, N. Pharaonic Lands in the Jezreel Valley in the Late Bronze Age. M. Heltzer e E. Lipinski (Eds.). Society and Economy in the Eastern Mediterranean (c. 1500-1000 B.C.). Leuven: 1988. p. 177-185.

. The Contribution of the Amarna Letters to the Debate on Jerusalem's Political Position in the Tenth Century B. C. E. Bulletin of the American Schools of Oriental Research (BASOR), n. 304, p. 17-27, 1996.

RAINEY, A. F. The El-Amarna Correspondence: A New Edition of the Cuneiform Letters from the Site of El-Amarna based on Collations of all Extant Tablets. Leiden-Boston: Brill, 2015.

Artigo submetido em 28.02.2018 e aprovado em 29.03.2018.

José Ademar Kaefer é doutor em exegese bíblica pela Katholisch-Theologische Fakultät der Westfälischen Wilhelms-Universität Münster, Alemanha (2004); tem pós-doutorado pelo Department of Archaelogy and Ancient Near Eastern Civilizations, Tel Aviv University, Israel (2016). Professor titular permanente do Programa de Pós-Graduação em Ciências da Religião da Universidade Metodista de São Paulo (UMESP). Orcid.org/0000-0003-1607-2810. jademarkaefer@gmail.com

Endereço: Rua Casper Líbero, 301, Bloco 11, Apto 103

09691-200 Pauliceia

São Bernardo do Campo - SP 